\title{
Effect of Temperature on Strawbale Wall Rendered with Laterite and Clay Nanoparticle
}

\author{
Adeola A. Adedeji ${ }^{3 *}$, Aminu Ibiyeye $^{2}$, Abiola $M$ Adedeji $^{3}$ \\ Department of Civil Engineering, Faculty of Engineering and Technology, University of Ilorin, Nigeria
}

\begin{abstract}
In this study, the influence of the plastering materials on the thermal performance of three (3) straw bale building models were evaluated. The plastering materials considered are laterite mortal, laterite mortal with nanoparticle clay screeding and cement-sand mortal. The results were based on the experimentally measured thermal conductance, thermal resistance and thermal transmittance of the building model according to ASTM C1045-90 standard specification. The analysis of the measured data revealed that the laterite plaster significantly improve the thermal resistivity of the building model compared to cementsand mortal. However, clay nano particle screeding on the laterite plaster does not significantly affect the thermal performance of the straw bale building model.
\end{abstract}

\section{INTRODUCTION}

With the ever increasing population of people in the world today and the global economic recession plaguing many countries of the world today, of which Nigeria (which is the most populous country in Africa and that with the highest annual growth rate in Africa) is not left out. Thus giving rise to the periodic increase in the demands for housing and the escalating cost of conventional building materials. Hence, the need to construct buildings with viable low cost materials has become a necessity in our fast growing society in other to overcome the problem in the housing sector [1]. With this problem at hand, there is need to develop alternatives, which have to be cost effective and create an ecological friendly room for the comfortability of the dwellers, due to the fact that some building materials may impair the ecological friendly condition of our rooms i.e. more economical, ecological friendly and readily available thus making this research important. One material that meets with these requirements is straw bale. It is an agricultural waste that is strong, cheap and readily available. Typical straw bale is shown in Fig. 1. The oldest surviving straw bale building is 107 years old, as of 2010 (US DOE,[2]). This structure, along with dozens of other straw bale buildings, was built by European settlers in the Sand Hills region of western Nebraska, USA at the turn of the 20th century.

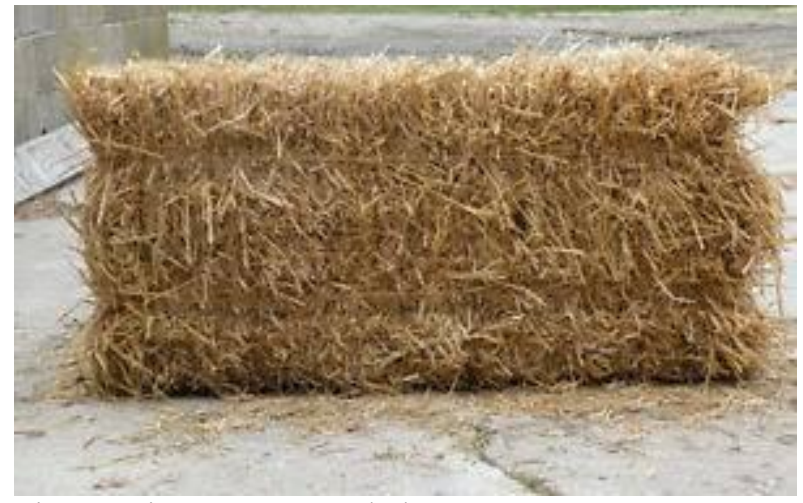

Fig. 1 Guinea corn straw bale

However, the environmental, physical and chemical properties of straws forming the bale strongly affect the durability of straw bale building. Part of the environmental conditions include temperature, relative humidity, Oxygen and $\mathrm{pH}$. If these conditions are conducive for micro-organism to thrive inside the bale, it leads to straw deterioration and negatively affect the durability of straw building [3]. Therefore, selection of suitable plastering material is very important for straw bale constructions. Hence, the thrust of this work was to study the thermal conductivity through the wall of a straw bale building plastered with laterite and clay nanoparticle materials.

Clay is one of the oldest building materials on Earth, among other ancient, naturally-occurring geologic materials such as stone and organic materials like wood. Between one-half and two-thirds of the world's population, in both traditional societies as well as developed countries, still live or work in buildings made with clay, often baked into brick, as an essential part of its load-bearing structure. Also a primary ingredient in many natural building techniques, clay is used to create adobe, cob, cordwoodand rammed earth structures and building elements such as wattle and daub, clay plaster, clay render case, clay floors and clay paints. It has also been used as a mortar in brick chimney sand stone walls where protected from water. Clays exhibit plasticity when mixed with water in certain proportions. However, when dry, it becomes firm and when fired in a kiln, permanent physical and chemical changes occur. These changes convert the clay into a ceramic material. Because of these properties, it is used for making pottery, both utilitarian and decorative, and construction products such as bricks, wall and floor tiles. Different types of clay, when used with different minerals and firing conditions, are used to produce earthenware, stoneware, and porcelain. Prehistoric humans discovered the useful properties of clay.

Currently, $45 \%$ of all the energy consumed in the world is used in the manufacture and transportation of such building materials (Earth Garden [4]). In addition, most standing structures are not in the least bit energy efficient. In the United States alone, as much as $70 \%$ of the electricity consumed and $40 \%$ of carbon dioxide emitted by residential homes is wasted due to the fact that many structures are poorly insulated and need 
excessive amounts of electricity and fuel to balance their energy inefficacies [5]. Energy and resource conservation have become a popular priority in today's construction industry. Whether it is to save energy costs or to genuinely act more sustainably, both commercial and non-for-profit interest groups have been growing more concerned on making buildings more "green". Green characteristics include efficient energy usage, water efficacy, decreased carbon dioxide emissions, increasing the utilization of natural light, and improvements in indoor air qualities. Current sustainable design and construction efforts can make energy efficient homes up to $90 \%$ less energy intensive than standard structures that are built to the same building code [5]. One method of building energy efficient structures is through straw bale construction. Building with straw bales has remarkable advantages that building with conventional materials such as wood, steel and concrete lack in terms of cost, abundance, and sustainability. However, the most distinct advantage of straw bale is that it is a highly efficient thermal insulator.

As this is true for individual grains of straw, baled straw is actually a very effective construction material because of its high density. To clarify the distinction between straw and straw bales, it can be compared to sheets of paper and a heavy bounded book. As sheets of paper are very weak and unstable individually, they work in the contrary when bounded together

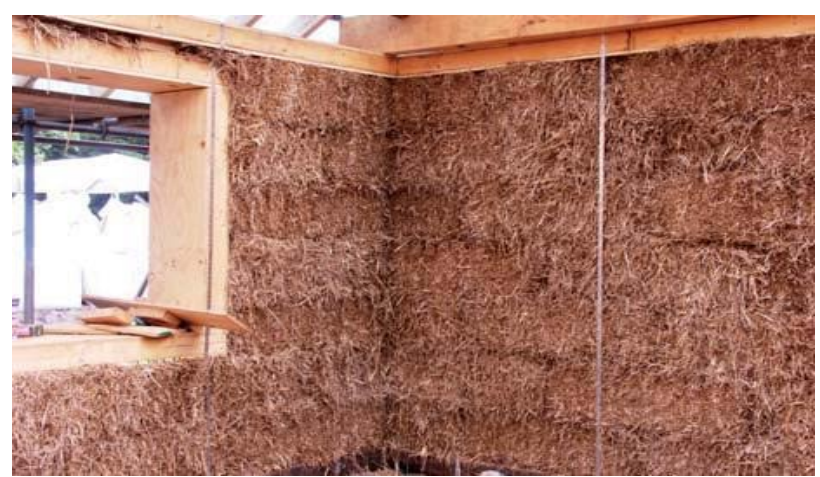

Fig. 3: Typical straw bale wall [4]

Another misconception concerning straw bale is that it is hazardous in terms of combustion. However, because straw bales are densely compacted, they are actually very fire resistant as there is limited oxygen within the bale to permit combustion. Fig. 3 shows a typical straw bale wall.

\section{Materials and Methods}

\subsection{Description of Straw bale building Model}

In order to evaluate the influence of plastering material on the thermal conductivity in a straw bale building, three building models (A, B and C) of the same scaled dimension of $400 \mathrm{~mm} \times 300 \mathrm{~mm}$ in plan and $400 \mathrm{~mm}$ in height on scale 1:100 representing a standard room of 4 $\mathrm{m} \times 3 \mathrm{~m} \times 4 \mathrm{~m}$, were constructed of straw bale wall. The thickness of the wall is $110 \mathrm{~mm}$.

\subsection{Materials}

The materials used for the study are: dry guinea corn straw with maximum diameter of $20 \mathrm{~mm}$, binding wire, laterite, earth clay, ordinary Portland cement of grade 42.5 conforming to BS 12 [6], naturally occurring river sand, portable water conforming to [7], wood for the window and door frame, asbestos for the ceiling and aluminium roofing sheets.

\subsection{Soil Characterisation}

The particle size distribution for the laterite material used for the rendering was determined by standard sieve analysis test while clay materials passing Nano sieve was used for the plastering. The moisture content of the soil samples was determined in accordance with BS 1377 [8].

The straws whose average diameter is $20 \mathrm{~mm}$ were cut into equal lengths of $400 \mathrm{~mm}$ to achieve the height of the scaled building model except at the window and door locations where the lengths were adjusted to fit the model geometry. The baling was achieved by vertically stacking the straws in a wooden mould until it is no longer possible to add more straws. The packed straws were tied together with binding wire at near the top quarter along the straw length. The baled straws were then carefully pushed out of the mould with the wooden base plate specially designed to achieve this, thereafter another binding wire were tied in turn at the middle and bottom quarter along the straw length to ensure adequate rigidity and firmness of the baled straws. Fig. 4 shows some of the baled straws

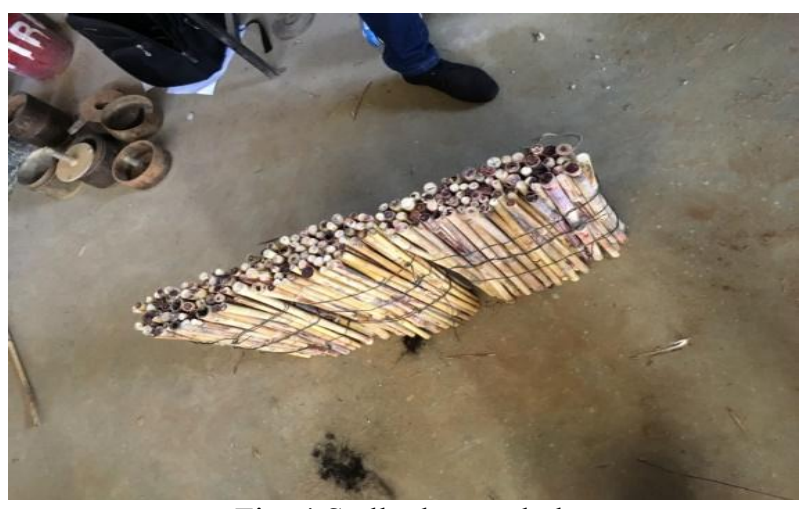

Fig. 4 Stalked straw bale

The straw bale walls in building model A was plastered with laterite mortal (laterite and water). The optimum moisture content for the laterite, determine in accordance with BS 1377 [8], was used to form the laterite mortal. Model B was similar to model A except that the laterite plaster was rubbed with nano particle clay mortal to achieve smooth surface. The control model, $\mathrm{C}$ was plastered with cement-sand mortal of 1:5 mix proportion. The thickness of the plastering for all the models was 15 $\mathrm{mm}$. The plastered straw bale wall was cured for 7 days before joining with mortal to form the building model. Fig.s 5 and 6 show the straw bale building model under construction. 


\subsection{Thermal Conductivity Test}

The thermal conductivity through the walls of the building models were measured in accordance with [9] standard specifications. The heating was generated through hot plate while the temperatures were recorded using a data logger with sensors positioned at surfaces of the wall (inside and outside), centre of the building model as well outside the building model. The test was carried out for both isolated (window and door closed) and open room conditions. The temperatures were recorded at intervals of 10 minutes over a period of one hour. Figs 5 and 6 show the experimental setup for the building model $\mathrm{A}$ and model $\mathrm{C}$.

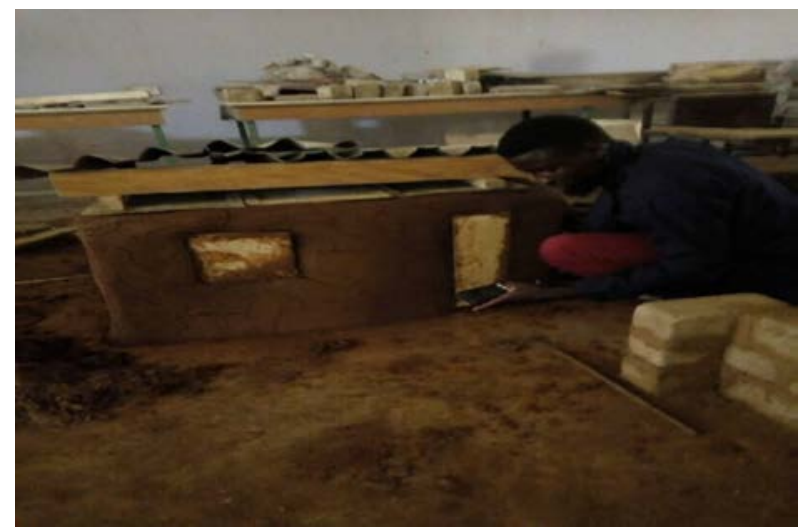

Fig. 5 Temperature test on model plastered with laterite

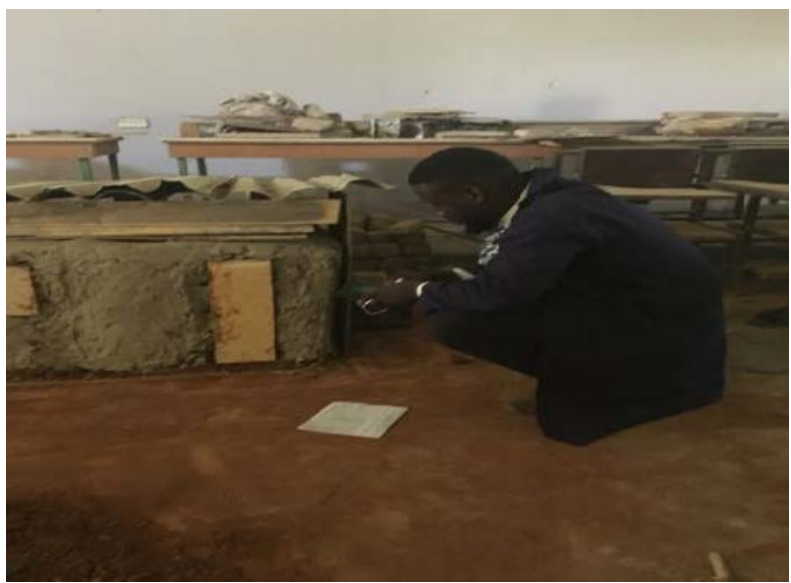

Fig. 6 Temperature test on model $\mathrm{b}$ plastered with laterite and rubbed with clay

The thermal conductivity (C), thermal resistivity (R) and thermal transmittance otherwise known as overall coefficient of heat transfer (U) for the models were obtained using the following models as given is ASTM C 1045[9]:

$$
\begin{gathered}
\mathrm{C}=\mathrm{QA}(\mathrm{Th}-\mathrm{Tc}) \\
\mathrm{R}=\mathrm{C}-1 \\
\mathrm{U}=\mathrm{QA}(\mathrm{T} 1-\mathrm{T} 2)
\end{gathered}
$$

Where: $\mathrm{Q}$ is the time rate of one-dimensional heat flow through the metering area of the test apparatus, $\mathrm{W}=$
$1200 \mathrm{~W}, \mathrm{~T}_{\mathrm{h}}$ is the area-weighted temperature of specimen hot surface, $\mathrm{K}, \mathrm{Tc}$ is the area-weighted temperature of the specimen cold surface, $\mathrm{K}, \mathrm{T}_{1}$ is the area-weighted air temperature $75 \mathrm{~mm}$ or more from the hot side surface, K, T2 is the area-weighted air temperature $75 \mathrm{~mm}$ or more from the cold side surface, $\mathrm{K}, \mathrm{A}$ is the wall area, $\mathrm{m}^{2}$

\subsection{Results and Discussions}

\subsection{Properties of the lateritic soil}

\subsubsection{Moisture content and Dry density}

Fig. 7 illustrates the graph of dry density against the moisture content of the laterite material used for the plastering. From the Fig., the optimum moisture content for the laterite is $8.7 \%$ while the maximum dry density is $17.77 \mathrm{~kg} / \mathrm{m}^{3}$.

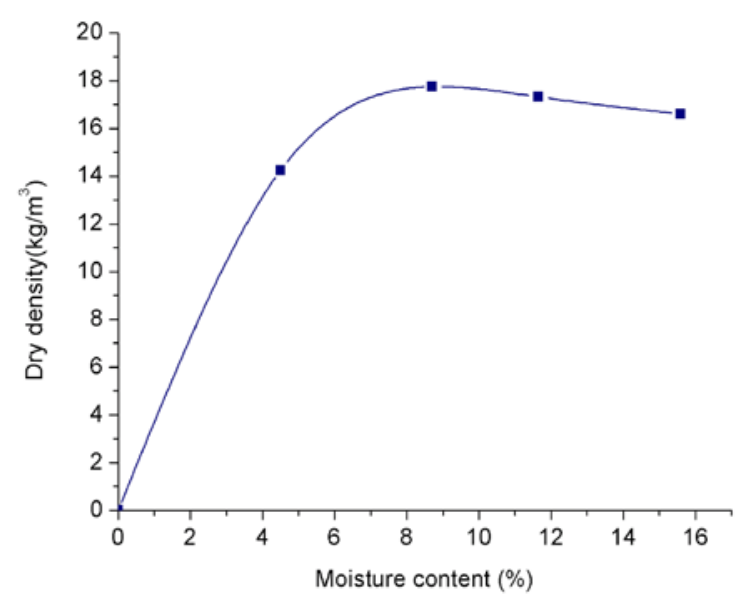

Fig. 7: Dry density versus moisture content for the Laterite material

\subsubsection{Particle size distribution}

The result of particle size distribution is necessary for soil classification. The particle size distribution for the laterite material is shown Fig. 4. From the graph, the following parameters were obtained:

$$
\begin{array}{ll}
\text { Effective size } & \text { D10 }=0.26 \mathrm{~mm} \\
\text { D30 } & =0.43 \mathrm{~mm} \\
\text { D60 } & =0.74 \mathrm{~mm}
\end{array}
$$

Coefficient of uniformity, $\mathrm{CU}=\mathrm{D} 60 / \mathrm{D} 10=2.85$

Coefficient of curvature, $\mathrm{CC}=(\mathrm{D} 30)^{2} /(\mathrm{D} 60 * \mathrm{D} 10)=$ 0.96

Fineness modulus, $\mathrm{FM}=$ (summation of $\%$ cumulative weight retained between $8 \mathrm{~mm}$ to $0.15 \mathrm{~mm}$ sieve size) / $100, \mathrm{FM}=2.82$

Therefore, the soil is classified as "Gravelly lateritic soil" and "A-2-6 Laterite according to the AASHTO classification system. 


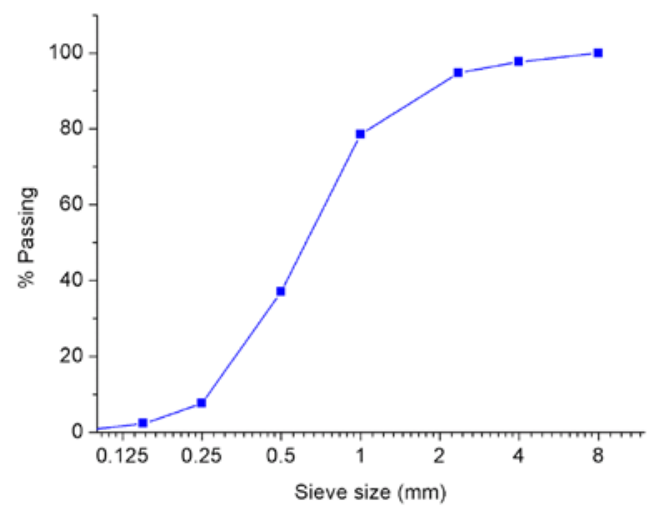

Fig. 8: Laterite particle size distribution curve

\subsection{Thermal Conductivity}

Fig.s 10 and 11 compared the results of thermal conductivity tests on the straw baled building models for closed and open room conditions. From the graph, the straw baled building plastered with cement-sand mortal (model C) has the highest thermal conductivity. The implication is that the thermal resistance of the cement sand mortal is lower compared to that of clay materials (model A and model B).

Therefore, the laterite mortal is more thermal effective than the cement-sand mortal. Furthermore, rubbing laterite render with clay nanoparticles does not significantly influence the thermal conductivity of the straw bale building models. Therefore, laterite plastered building (model A) and laterite plastered model rubbed with nano particle clay (model B) showed similar thermal performance.

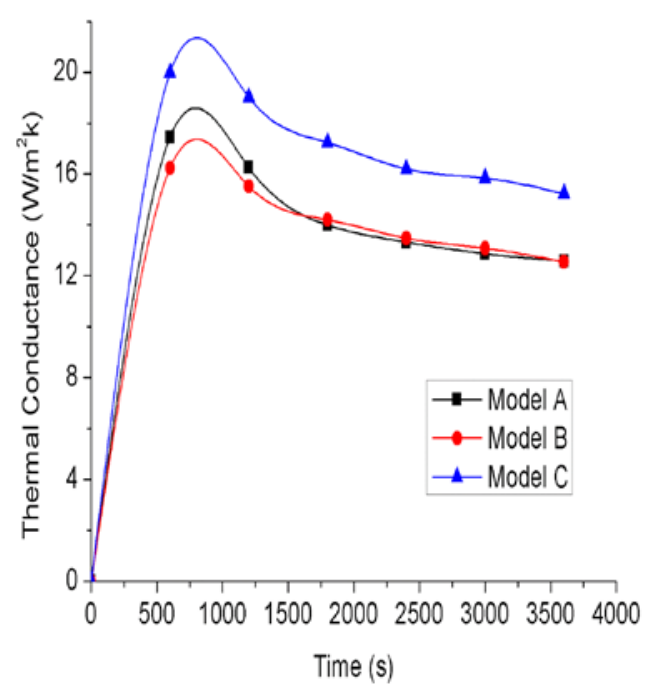

Fig. 10 Thermal conductivity versus time for opened strawbale building

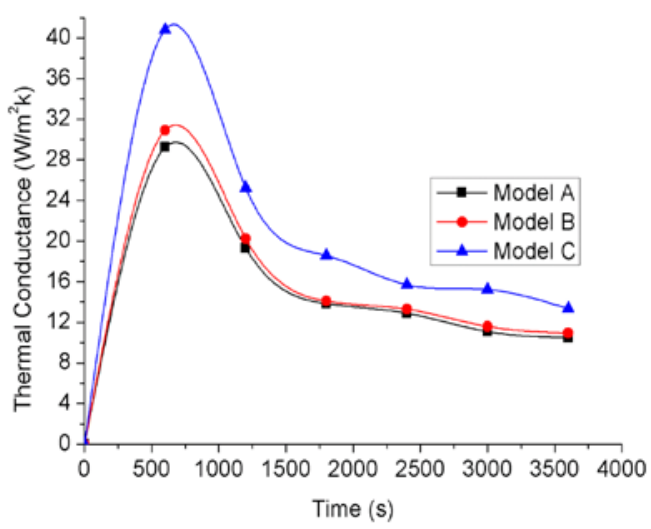

Fig. 9 Thermal conductivity versus time for closed/isolated strawbale building

\subsection{Thermal Transmittance}

Fig.s 8 and 9 also compared the thermal tranmittance values for the straw baled building models under closed and open room conditions. The result is similar to that of thermal conductivity. The straw baled building plastered with cement-sand mortal (model C) showed the highest thermal transmittance.

This implies that the laterite material provides beter thermal insulation for both the straws inside the walls as well as the surrounding environment. However, the thermal performane of laterite plastered building (model A) and laterite plastered model rubbed with nano particle clay (model B) are not significantly different. This shows that the thermal insulating properties of both the clay and the latrite are very similar.

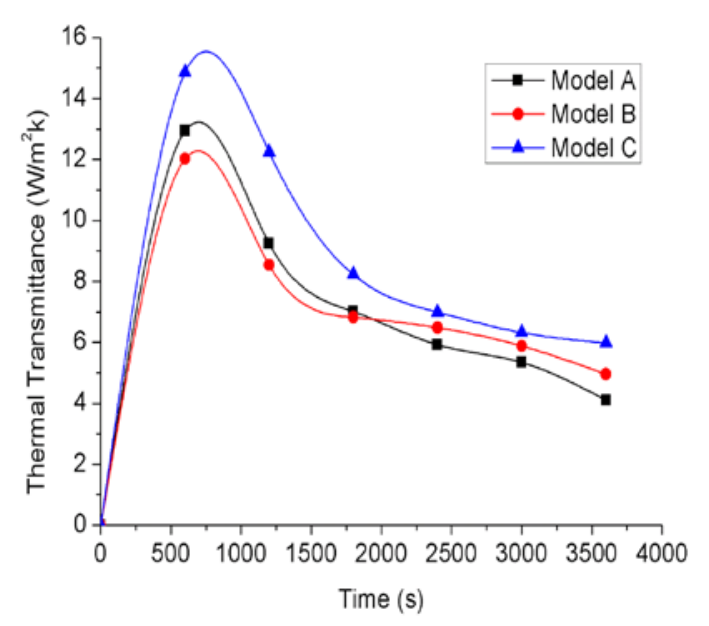

Fig. 10 Thermal conductivity versus time for opened strawbale model 


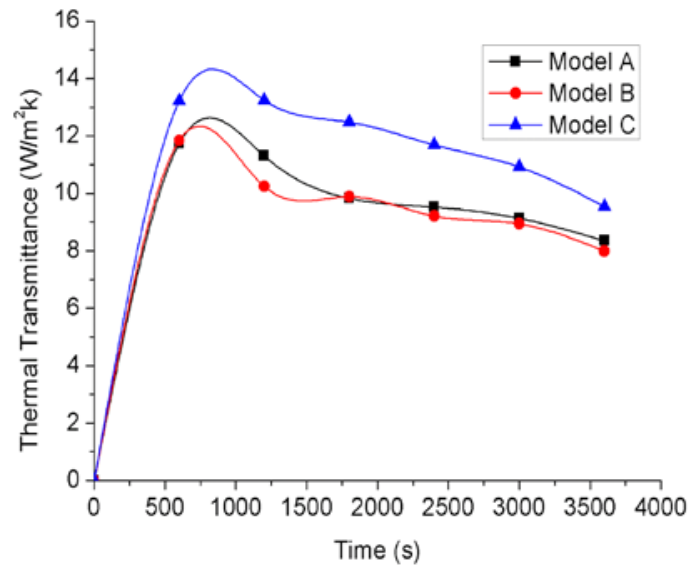

Fig. 10 Thermal conductivity versus time for closed/isolated strawbale building model

\section{Conclusion}

In the present study, the thermal performance of straw bale building plastered with cement-sand mortal and laterite mortal were evaluated. From the study, it is concluded that: The thermal performance of a straw bale building depends on the plastering material. The thermal resistivity of the laterite plastered wall was found to be greater than that of cement-sand mortal. The thermal transmittance in cement-sand plastered straw bale building is higher compared to straw bale building plastered with laterite mortal. Clay screeding does not significantly influence the thermal performance of laterite plastered straw bale wall.

\section{References}

1. A. A. Adedeji. Introduction and design of straw bale masonry, Olad publishers Ent., Ilorin. (2007).
2. U.S Department of energy, straw bale construction and building code, Assessed onlin: http.//www.thelaststraw.com.

3. Ashour, T., Georg, H., \& Wu, W. (2011). Performance of straw bale wall: A case of study. Energy and Buildings, 43(8), 1960-1967, (2011)

4. Earth Garden. Straw Bale Home Building. Maryborough, Australia: McPherson's Printing Group.greenhomebuilding.com. (n.d.). Retrieved September 7, 2010, Assessed online: http://www.greenhomebuilding.com/strawbale.httm, (2014).

5. 5. Jafferiji H., Karina R. and Yao W., Straw bale Construction: The Application in Massachusetts. Thesis submitted to the faculty of Worcester Polytechnic Institute (WPI), Worcester. (2011).

6. FWS, The sandhills: building partnerships for an Ecosystem. U.S. Fish and Wildfish Service. Retrieved1 June 2010 from http://www.fws.gove/mountainprairie/pfw/ne/ne4.httm. (2010).

7. 7. ASTM C1045 Standard Practice for Calculating Thermal Transmission Properties Under SteadyState Conditions, American Society for Testing and Materials ASTM, West Conshohocken, PA. (1997).

8. 8. A. A. Adedeji, Evaluating Thermal Resistivity of a Cement Plastered Straw Bale Wall: A Review" Department of Civil Engineering, University of Ilorin, Ilorin, Nigeria.(2011).

9. Mehmet F. A, Ahmet E.T and Omer F.C. Strawbale Houses: A Quick Solution to Accomodation Problem.'3rd International Conference on Sustainable Construction Materials and Technologies, Assessed from http://www.classie.info/Proceedings.htm on $4^{\text {th }}$ February, 2017. 